\title{
A Systemic Framework to Evaluate Student Satisfaction in Latin American Universities under the COVID-19 Pandemic
}

\author{
Silvia Quispe-Prieto ${ }^{1}$, Melissa Franchini Cavalcanti-Bandos ${ }^{2} \mathbb{D}$, Manuel Caipa-Ramos ${ }^{3}$, \\ Alberto Paucar-Caceres ${ }^{4, *(D)}$ and Héctor Heraldo Rojas-Jiménez ${ }^{5}$ (D)
}

check for

updates

Citation: Quispe-Prieto, S.; Cavalcanti-Bandos, M.F.;

Caipa-Ramos, M.; Paucar-Caceres, A.; Rojas-Jiménez, H.H. A Systemic

Framework to Evaluate Student Satisfaction in Latin American Universities under the COVID-19 Pandemic. Systems 2021, 9, 15. https://doi.org/10.3390/ systems 9010015

Academic Editor: Ockie Bosch

Received: 29 November 2020

Accepted: 5 February 2021

Published: 12 February 2021

Publisher's Note: MDPI stays neutral with regard to jurisdictional claims in published maps and institutional affiliations.

Copyright: (c) 2021 by the authors. Licensee MDPI, Basel, Switzerland. This article is an open access article distributed under the terms and conditions of the Creative Commons Attribution (CC BY) license (https:/ / creativecommons.org/licenses/by/ $4.0 /)$.
1 Escuela Profesional de Enfermeria, Universidad Nacional Jorge Basadre Grohmann, Tacna 23003, Peru; squispep@unjbg.edu.pe

2 Centro Universitário Municipal de Franca-Uni-FACEF, Franca, Sao Paulo 14401 135, Brazil; melissa@facef.br

3 Departamento Academico de Ingenieria Comercial, Universidad Nacional Jorge Basadre Grohmann, Tacna 23003, Peru; mcaipar@unjbg.edu.pe

4 Faculty of Business and Law, Manchester Metropolitan University, Manchester M15 6GH, UK

5 Facultad Finanzas, Gobierno y Relaciones Internacionales, Universidad Externado de Colombia, Bogotá 111711, Colombia; hector.rojas@uexternado.edu.co

* Correspondence: a.paucar@mmu.ac.uk; Tel.: +44-161-247-3832

\begin{abstract}
Latin American universities (LAUs) have been going through a serious lack of economic resources which has plunged them into a deep financial crisis. The COVID-19 pandemic has exacerbated this calamity. However, LAUs have implemented online teaching processes in order to mitigate the effects of scheduling and other classroom disruption. There is evidence that these modes of teaching have had a reasonable reception but the level of student satisfaction is yet unknown. This article takes a systemic view of the predicament facing LAUs. It represents the elements related to the disruption caused by COVID-19 in a rich picture, building a systemic framework to explore student satisfaction with remote teaching. Using a sample of 298 students from Brazil, Colombia, and Peru, the study analyzes their situation through: (a) Well-being, educational resources, and learning experience and; (b) General satisfaction with virtual classes. Applying exploratory factor analysis, this study identifies three dimensions: (a) satisfaction with support and adaptation in the virtual modality; (b) satisfaction with the interaction in the virtual classroom; and (c) satisfaction with the development of the study program. Medium/high scores for the dimensions indicate moderate/high levels of satisfaction. The findings suggest that there are still unsatisfied needs regarding access to digital resources and socio-emotional needs. This article could be of interest to Higher Education Institutions (HEI) planners dedicated to post-pandemic, virtual education.
\end{abstract}

Keywords: COVID-19; systems thinking; education; factor analysis; Latin America; satisfaction

\section{Introduction}

At the time of writing this paper [mid November 2020], the Coronavirus Disease 2019 (COVID-19) has infected more than 53 million people, causing 1.3 million deaths across the world [1]. The pandemic abruptly erupted in all areas of our society and education (at all levels) has been one of the sectors most affected. UNESCO reports the massive closure of educational institutions in more than 190 countries in order to prevent the spread of the virus and mitigate its impact and, in May 2020, more than 1200 million students of all educational levels have stopped having classes face-to-face. Among this group, more than 160 million were students from Latin America and the Caribbean [2]. Likewise, millions of university students are abandoning their university studies as a consequence of the changes that they were forced to carry out due to the implementation of strategies for continuing studies [3].

It is well known that even before the pandemic, education in the Latin America (LA), faced many unsolved problems. For some time now, this sector has been characterized 
by underfunding, inaccessibility, and extreme levels of inequality. However, over the last decades, governments in the region have made efforts to invest in basic education programs as well as to implement and improve the quality of universities. As a result of these efforts, since 2000, the enrolment figures for higher education in Latin America actually doubled from $21 \%$ to $40 \%$ to 2010 of the university population [4]. Even beyond such statistics, the pandemic has exacerbated the structural problems of education inequality and inaccessibility that still plague many Latin American countries.

The pandemic is putting the situation of access to universities at serious risk of setback. The Times Higher Education Supplement (THE) reports that Latin American universities were already lagging behind those in other regions of the world before the pandemic. According to THE World University Rankings 2021, there is not a single Latin American university among the top 200 in the world [2]. Representing this region in 240th place, the University of Sao Paulo, Brazil is followed by other Latin American universities, (yet, with the risk of falling lower in the ranking due to the closure of universities) [2].

The three countries referred to in this paper all share similar challenges in terms of accessibility to education and dropout from studies. In the last 10 years, Colombia had an improvement in its higher education coverage rate (Indicator that shows the relationship between students enrolled in the upper undergraduate level and the population between 17 and 21 years old) and a percentage increase of 21 points in 2015. This was evidenced when compared with the 2005 Census, which was 28.4\% [5]. However, findings for 2018 reveal (for the first time) a change from a constant increase in students in universities to a decrease [6]. Meanwhile, the dropout rate by cohort shows $48.3 \%$ in 2005 and increased to $50.7 \%$ in 2015. Consequently, half of the students who start university studies drop out of the educational system [5]. In addition, due to the pandemic, enrolment is expected to decrease by up to $25 \%$ [6].

The situation in Brazil is similar. This country had already been facing accessibility problems. There is a very complex and unequal higher education system, an annual dropout rate of $18.3 \%$ and a phenomenon of expansion of the university system closely associated with the growth of the private sector [7]. In this country, a recent study concluded that $42 \%$ of students from private universities are at risk of abandoning their studies because they cannot pay their semester fees [8].

In Peru, according to the Instituto Nacional de Estadística e Informática (INEI) figures, between 1996 and 2010, the number of universities has grown from 57 to 100 but this was in an unplanned, disorganized, and haphazard manner. Additionally, the number of public universities increased by $25 \%$ (from 39 to 51 universities), while the number of private universities increased by $124 \%$ [8] (from 40 to 91 universities) to the year 2014) [9]. Likewise, the number of students enrolled in universities from 2007 to 2017 increased from 649,499 to $1,279,738$ [10]. However, as a result of the pandemic, 174,544 students suspended their studies, mainly due to lack of connectivity to follow remote education and another cause was due to lack of financial resources [11].

The pandemic has meant that university students have been affected by the closure of their study centers, in Colombia $(2,408,041)$, in Brazil $(8,571,423)$, and in Peru $(1,895,907)[12]$. Likewise, universities are facing global challenges such as: opting for virtual teaching, having to guarantee continuity and commitment to study by their students, in addition to the traditional problems common to that level of studies.

One of the problems that universities face when implementing virtual teaching is the lack of a technological platform, despite efforts to integrate into the digital field since the 1980s. Since then, the main concern has been to strengthen students' digital skills. This situation is common in Latin American and Caribbean countries that are unequally prepared to face this crisis by taking advantage of digitization [13].

For many students with problems of connectivity, provision of digital equipment and health due to socioeconomic problems, virtual teaching generated dissatisfaction mainly at the beginning of classes. Some students triumphed over these problems because of support 
from their institutions and their own families. Despite this, there are many cases that have ended in desertion of studies.

Evidence about student satisfaction under the new virtual modality is unknown. This represents a weakness for every institution. Such evidence would make it possible to provide solutions aimed at responding to the challenges of academic security, quality of education, and accessibility. This is in order to guarantee the training of professionals with improved competencies, irrespective of the current pandemic [14].

However, due to the urgency of the current situation, Higher Education Institutions (HEI) in LA have had to develop additional skills in their education processes. This includes the mechanisms for evaluating student satisfaction. A quick review of these efforts reveals that they are made from a mix of traditional methods of offering education and reference to different virtual education platforms.

According to Aristovnik et al. [15] (p. 2), several papers have already been published by researchers around the world presenting studies on various aspects of the COVID-19 pandemic crisis:

Particularly its consequences for physical and mental health, the economy, society and the environment. The biggest limitations of these studies about student life while their higher education institution is physically closed are generally: the data derive from early stages of the pandemic; a relatively small sample; and focusing chiefly on a restricted number of aspects of a student's life. Indeed, most studies are limited to academic work or life issues, a student's mental health or a combination of both.

Álvarez, et al. [16] consider that the student is not a client, nor the passive recipient of a service, researching student satisfaction clearly contributes to improving the quality of educational services, it is necessary to make improvements in educational services. Thus, inviting student commentary about their satisfaction with the quality and competitiveness of their educational institution is important.

The quality of the university's service benefits, when students express their views about the characteristics of the teaching delivery, context, and interaction with their inclination to study. Such characteristics can be considered as external and internal aspects of the student life that influence the individual's academic satisfaction. [17].

Finally, a practical approach to a satisfaction evaluation model is offered by RosarioRodríguez et al. [18], where they used a non-experimental cross-sectional exploratorydescriptive design, in a sample of 167 students from 17 different universities in Puerto Rico. The main objective of this research was to examine the technological, academic, and psychological demands that Puerto Rican HEI students may be experiencing during the COVID-19 pandemic. The main results entailed: problems related to stressors due to overload of assignments, poor implementation of online courses, lack of guidance from their universities, and little flexibility from their professors, among others. These results open the way to study sudden changes in educational modality (transfer from face-to-face to the online approach) and their impact on students, Rosario-Rodríguez et al. [18].

In this research, we wanted to investigate this further, and using systems concepts, we attempt to explore from the perspective of the students their experiences and satisfaction with the virtual modality of studies adopted by the three HEIs in our sample: Municipal University Centre of Franca (Uni-FACEF) in Brazil; Externado University of Colombia (UEC); and Jorge Basadre Grohmann National University (UNJBG) in Peru.

At almost ten months from the beginning of the pandemic, a period in which universities have implemented online teaching, there are very few studies assessing the adequacy of this methods and the satisfaction experienced by students. There were studies that have examined students' satisfaction in conditions prior to the pandemic. The models to study satisfaction have used a mix of quantitative and qualitative approaches. This study acknowledges these studies but we believe that only by taking a systemic view, can the concerns and needs and therefore satisfaction of students can be assessed. To cope with the interruption, HEIs had to mobilize a set of software tools to replace normal methods, 
tools to re-write academic content of entire units, and then to evaluate their reception and efficacy. It is in this area of assessing the efficacy and effectiveness of the new modes of teaching and its reception by students that the present research concentrates. We aim to identify the key elements that underpin students' satisfaction or dissatisfaction in three countries most badly hit by the pandemic in the Latin American region.

Until a few years ago, the nature of management sciences applications were characterized by the use of a particular technique, method, or methodology and by aligning itself with a particular unique paradigm, traditionally labeled as hard/quantitative or soft/qualitative. However, in the last two decades, management scientists and indeed systems practitioner, academics, and consultants have begun to combine methods, methodologies, and techniques not only from a single paradigm, but from various paradigms simultaneously $[19,20]$. This mode of practice has been coined as multi-methodological practice. The approach used in this paper follows that trend in that we combine systemic tools and concepts to explore the initial phases of the problem tackled and then we use quantitative techniques such as factorial analysis to investigate student's expectations during the pandemic.

The paper is organized as follows: After this introduction, in Section 2, using some basic systems principles, we set out the systemic framework used to explore the complexity faced by universities at the outset of the pandemic. In Section 3, we outlined the research questions derived from the main relevant issues derived from the systemic analysis drawn from the previous section. In Section 4, we outline the methodological stages to explore the key satisfaction dimensions amongst a sample of students in the three countries. Results of survey and factor analysis: exploring students' satisfaction are presented in Section 5. In Section 6, we discuss the results of the survey. In Section 7, we advance some final remarks as to how our findings might affect educational policy, we also acknowledged the limitations of our study together with some ideas for further research.

\section{Conceptual Framework and Model}

\subsection{Systems Thinking: Exploring and Tackling Complexity of a Pandemic}

The consequences of the pandemic have been felt in every sector of society and every aspect of life. At the moment of writing this article [mid-November 2020], there are fears of a second-wave of infections and there are no signs of a permanent solution to the problem or even of abating the epidemic consequences-at least in the short term. We might be approaching a scenario in which we expect only partial improvements of a messy situation. What is becoming more apparent is that the pandemic and its consequences cannot be explored using deterministic and reductionist-informed tools. These do not pay enough attention to 'connections' - to the myriad of elements or parts that conform what can only be classified as an extremely complicated, problematic situation.

Our contention is that, to tackle the complexities of COVID-19, it is imperative to take a systemic (not systematic) view. Systems thinking (ST) as a discipline and as a way of thinking can be traced back to Aristotle: "The whole is more than the sum of its parts". ST focuses and explores the interactions between the constituent elements of a system, offering a holistic inquiry of such systems in contrast to reductionist approaches. It has been applied extensively to many fields of knowledge and organizational settings and yields effective results when problematical situations or 'messes' are most recurrent. Ackoff [21] (p. 1) urges us to take a systemic perspective: "Almost every problem confronting our society is a result of the fact that our public-policy makers are doing the wrong things and are trying to do them righter."

Furthermore, when we approach complexity, it is worth to remember what systems thinking is and why it is important to differentiate between a collection of parts and a systems. As Kim [22] (p. 2) states: '[ . . . ], a system is any group of interacting, interrelated, or interdependent parts that from a complex and unified whole that has a specific purpose. The key to remember is that all parts are interrelated and interdependent in some way. Without such interdependence we have a collection of parts, not a system'. 
Debates about the handling of the effects COVID-19 have increased interest in systems thinking in the field of health, healthcare, and medicine. Two recent online publications suggest the necessity to use ST: (1) COVID-19 means systems thinking is no longer optional [23]; and (2) A systems approach to preventing and responding to COVID-19 [24].

Furthermore, the urgency for ST to cope with the COVID-19 aftermath has been echoed recently by the OECD [25]:

[ ... ] policy interventions and priorities to address COVID-19 must incorporate principles of system resilience to systemic disruption now, for not doing so will limit future socioeconomic recovery for the next decade at least. Systems thinking is the most powerful tool we have at our disposal to accomplish this task, if it is part of a trilogy completed by anticipation and resilience.

In this paper, we aim to use some ST principles to first explore the situation the pandemic has presented; and tried to take various perspectives from which to assess its consequences. The context in which this is unfolded will be the processes that universities have put in place to mitigate the pandemic disruption effect. We plan to use the systemic tools to explore the success of these teaching and learning plans and, to assess how this fared, in terms of overall university student satisfaction, in the three Latin American countries.

\subsection{Conceptual Framework of the Study}

In order to carry out the study and try to answer the research questions (RQs), the conceptual framework informing the study adopted is based on systemic principles and follows the Four 'As' model or stages of a systems study proposed by Mingers and Brocklesby [26]. The four stages should be followed as an iterative (not sequential) process in that during the study, returning to the previous stage and refining the model are encouraged. The four As are: Appreciation, Analysis, Assessment, and Action. We start by appreciating and trying to make sense of the situation by surveying and structuring the problematic situation. The second analysis is aimed at identifying the possible variables and relationships between them, in the context of the problematic situation. We then assess or evaluate ways to control or eliminate those causes, while the fourth establishes and implements the action plans. The general framework is shown in Figure 1.

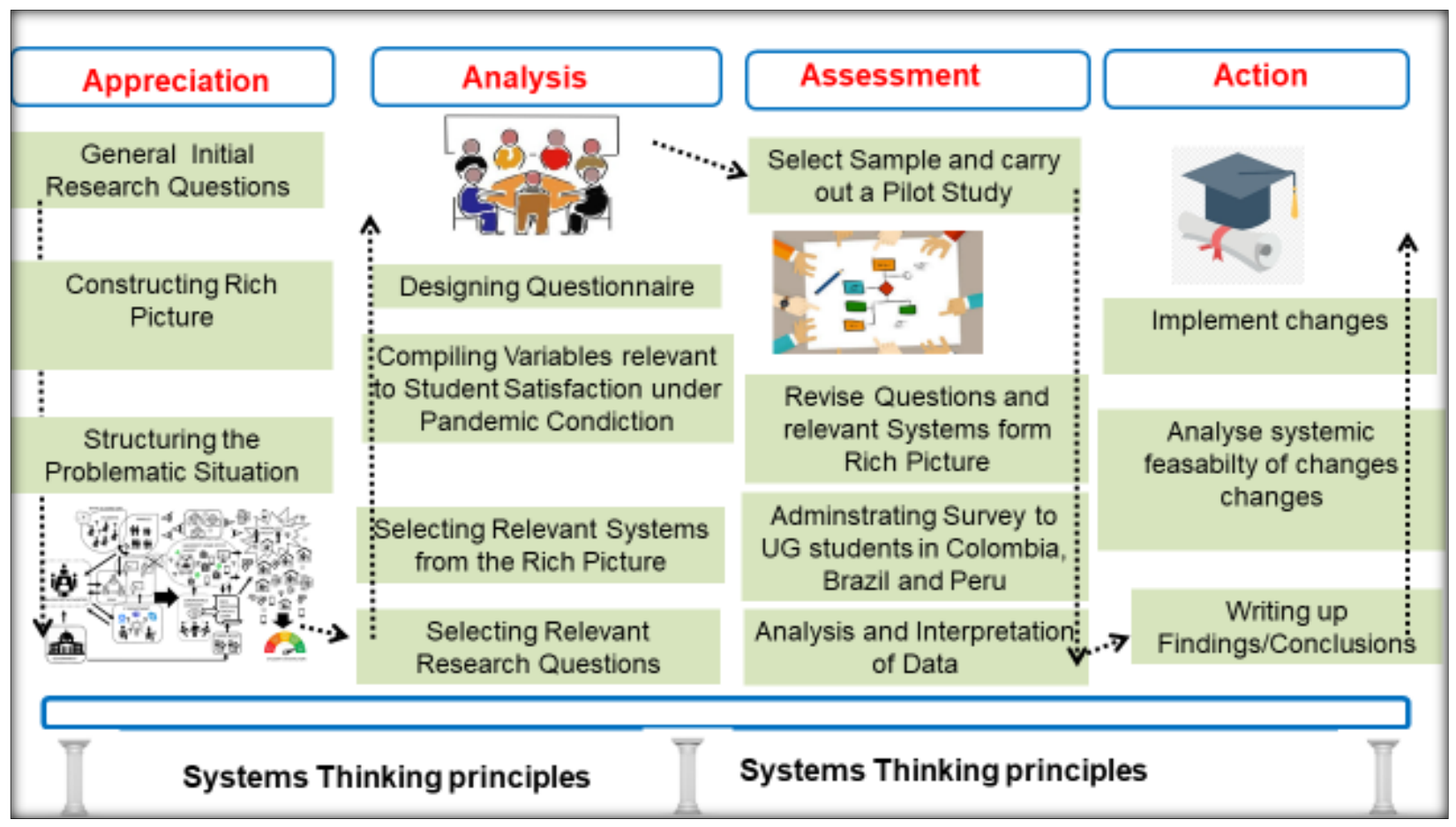

Figure 1. Conceptual framework and methodological stages of the study (adapted from [26]). 
Having the relevant issues and research questions outlined in Table 1, we followed the four stages of this framework depicted in Figure 1.

- Appreciation: Firstly, the project team appreciated the situation by searching for the main variables that affected the process. Then, we built the rich picture with all the elements. This was in order to be able to interpret the whole problematic situation. We then structured the problematic situation to be able to see the whole- -through the correlations between the variables.

- Analysis: Secondly, from the rich picture we selected four relevant research questions and designed the questionnaire by compiling relevant variables to student satisfaction under the pandemic context.

- Assessment: The third stage of assessment and interpretation of the data followed. We selected a sample to carry out a pilot study with 298 students in one of the countries involved. To complete the Analysis stage of our conceptual framework, we revised the questions and the relevant systems formed in the rich picture, and applied the survey with 298 Colombian, Brazilian, and Peruvian students. This was done using Google forms. As will be fully explained later on in the paper, the project team complied with ethical protocols set out by the three universities involved for this type of study. Specifically, we made students aware that they were being invited to academic research. There was voluntary participation and their anonymity and confidentiality were guaranteed.

- Action: Finally, we wrote the findings and conclusion together with and analysis of the systemic feasibility of changes that need to be implemented.

Table 1. Relevant systems and research questions to study.

\begin{tabular}{|c|c|}
\hline Relevant Issues and Relevant Systems & Research Questions \\
\hline $\begin{array}{l}\text { - } \quad \text { Continuity of classes; } \\
\text { - } \quad \text { Safety of lecturers and students; } \\
\text { - } \quad \text { Learning. }\end{array}$ & $\begin{array}{l}\text { RQ1: What are the main issues of concern faced by LA HEI in } \\
\text { dealing with the consequences of the pandemic? }\end{array}$ \\
\hline $\begin{array}{l}\text { - Quickly trained lecturers for online teaching; } \\
\text { - } \quad \text { Invested in video conference tools to make classes possible; } \\
\text { - } \quad \text { IT support personnel for eventual contingencies. }\end{array}$ & $\begin{array}{l}\text { RQ2: What are the main measures taken by LA HEI to deliver } \\
\text { their teaching and learning objectives under the current crises? }\end{array}$ \\
\hline $\begin{array}{l}\text { - Tool for accessing classes: cell phone, notebook, computer; } \\
\text { - Infrastructure problems: internet; } \\
\text { - Tiredness of students and lecturers in the face of the } \\
\text { new situation; } \\
\text { - Possible diseases throughout COVID-19 process: Mental and } \\
\text { Health problems. }\end{array}$ & $\begin{array}{l}\text { RQ3: What are the main variables affecting students teaching } \\
\text { and learning objectives under the current crises? }\end{array}$ \\
\hline $\begin{array}{l}\text { - Adaptation of students/lecturers with the new protocol to } \\
\text { "Teach and Learn"; } \\
\text { - Safety and tranquillity during learning in a } \\
\text { Pandemic Context; } \\
\text { - Feedback from the students during this experience. }\end{array}$ & $\begin{array}{l}\text { RQ4: How satisfied are students with the new teaching } \\
\text { arrangements and how these can be improved? }\end{array}$ \\
\hline
\end{tabular}

Source: authors.

\subsection{Rich Picture and Relevant Systems}

To structure the situation and these questions, the project team worked via a series of Zoom meetings and similar platforms. We gathered perspectives and stories about how HEIs in Brazil, Colombia, and Peru are coping with the unfolding of the pandemic. We all agreed that this was a situation featuring hard and soft complexity which can be characterised as a mess [21], or a wicked problem in that 'evades a definitive formulation', [27,28].

We follow some of the concepts proposed by Checkland [29], when faced with a messy problem. We try to structure it by drawing a rich picture (RP) that contains as much of the information, variables, people, institutions, and relationships of problematic situations 
provoked by the pandemic. Rich picture techniques have been used extensively in systems studies, particularly as a first step to make sense of a messy situation. The UK Open University has developed a good repository of advice as to how to use this technique [30].

Using this basic and simple technique, we first drew a RP of the situation. This $\mathrm{RP}$ was constructed via an iterative exercise conducted via various Zoom sessions, with collaborative input from the project team members. Figure 2 shows the final version of the RP. It is worth stressing that this is by no means a picture that contains all the variables interacting in this situation but it contains the world views (arguably subjective) of the project team at the time; and, it is a snapshot of the situation at the moment in which it was constructed (end of October 2020).

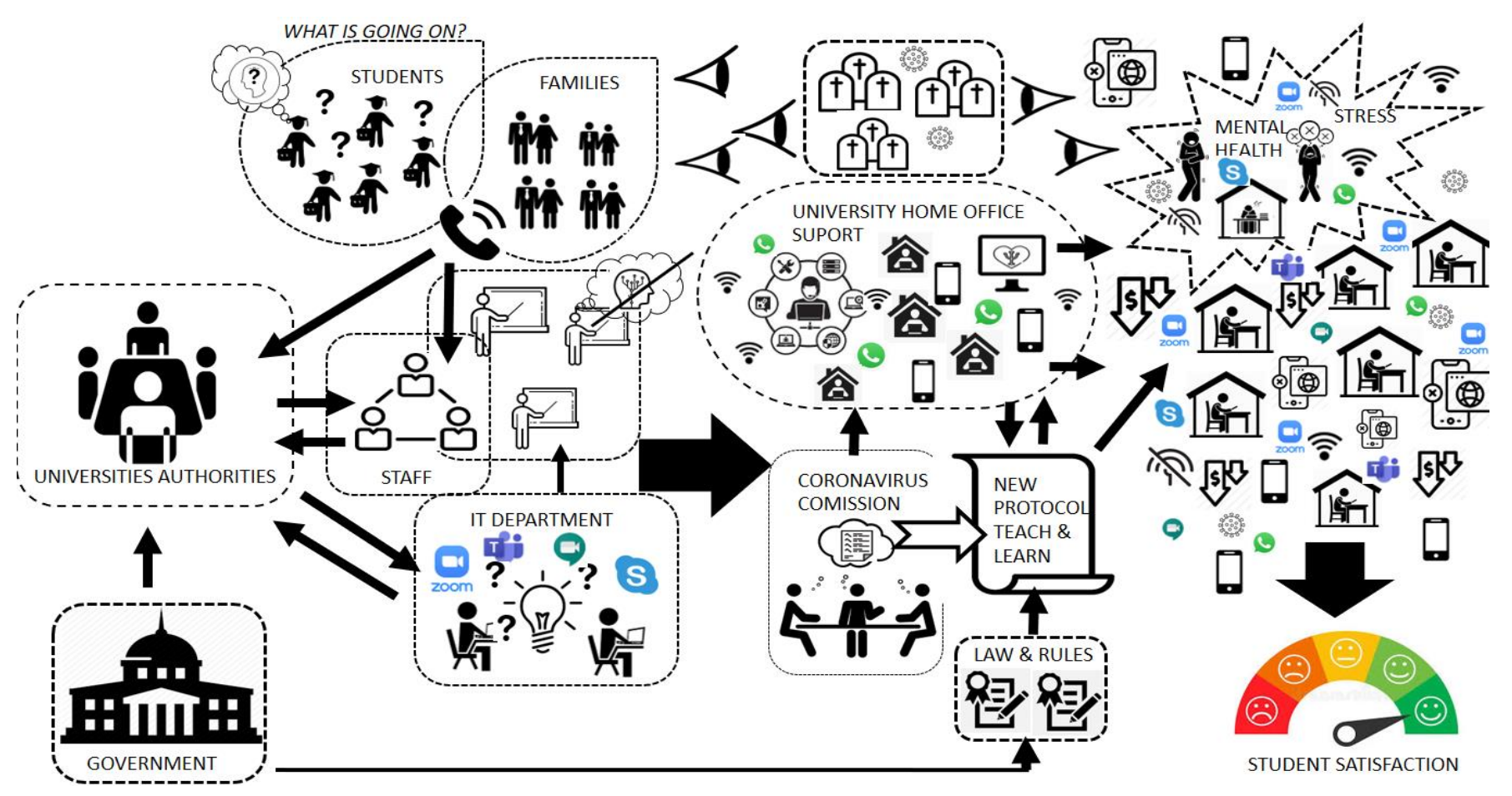

Figure 2. A rich picture of the consequence of the pandemic with emphasis on the education system. Source: authors.

Looking at Figure 2, we can see two distinctive parts: the left side, containing information when the problem started and the right side, with the consequences of the HEI lockdown.

On the left side, events of the beginning of March 2020 are depicted. The LA HEI authorities and staff started received phone calls and enquires from the students' families, asking about: the particular university's position regarding the appearance of COVID cases, worries about the students' own safety, and concerns about the increase in the number of deaths. The LA university authorities decided to close their universities. This decision followed the world trend and the rules imposed by the government. Some universities, at this time, already had a pandemic committee created. Without face-to-face classes, the IT department had to provide technological options to make distance classes feasible.

On the right side of the picture, relevant results and consequences are presented together and the implementations are depicted: all the university staff started working online from home; a new protocol: "Teach and Learn" was created and the lecturers had to change and adjust their mental models from face-to-face classes to live online teaching. Difficulties in adapting to this new mode of teaching are depicted by the number of arrows relaying this item and other problems that emerged (such as difficulty with equipment, internet and wireless connections). As it well known, everybody had to develop new mental models and adapt quickly to the new unprecedented circumstances, creating anxiety (which in themselves caused more anxiety from the full lockdown). Mental and 
health problems definitely surfaced among the actors involved: university staff, lecturers, students, parents, etc.

In a systems study, the RP is to have a general view of the situation. As it can be seen in the RP, there are various areas of concern. The project team comprised mainly lecturers who, having experienced the stress and anxiety at first hand, decided to concentrate on issues affecting student learning and teaching and the impact on student satisfaction. In the next subsection, we develop these relevant systems in some detail, structured according to the shape of research questions guiding the rest of the study.

\section{Relevant Issues and Research Questions}

As mentioned above, from the rich picture, we extracted some relevant systems that the project team thought were actually connected to student satisfaction. Using the RP as an initial point (and, after various online sessions various issues were considered important), the team decided to address the following issues around four research questions (RQs). These are summarized in Table 1 immediately below.

\section{Methodology: Using Factor Analysis to Explored the Students' Satisfaction Factors}

The study focuses on effects of the virtual teaching modality in the framework of the COVID-19 pandemic at a university in Brazil, Colombia, and Peru, respectively. Initial and preparatory stages have been completed by systematizing techniques and procedures that have allowed, through observation and measurements, to quantify the data of the study variables. Such systematization provided description objectives on aspects related to the experiences of students on well-being in the face of a pandemic study as well as their satisfaction with the university institutional performance. A quantitative approach was followed with an instrument that made it possible to configure three dimensions per data grouping.

\subsection{Data \& Method}

An observational, analytical cross-sectional study was carried out in the months of August and September 2020 in the schools of Accounting and Business Sciences of the HEI of the Municipal University Centre of Franca (Uni-FACEF) in Brazil; Externado University of Colombia (UEC); and Jorge Basadre Grohmann National University (UNJBG) in Peru. Students were drawn from their 1st to 5th year; the study complied with the ethical protocols of each university and gained approval from the management of the mentioned schools.

\subsection{Data Description}

The population comprises students of the three universities programs; the sampling method was non-probabilistic. The inclusion criteria considered students enrolled in the first academic semester of 2020. The sample was made up of 298 students (Brazil 99; Colombia 80; Peru 119). All students in the sample were previously informed of the study objectives and their consent to answer a questionnaire in virtual mode was gained.

The data for the research come from an anonymous and self-administered survey in a virtual way through the Google Form computer application. The participants were located in some cases in their virtual study rooms, and in other cases, contacted through their groups organized by WhatsApp. Once contacted, the instrument location link was explained to them and the Google Form was sent in. The responsible researchers were the members of the research team, who coordinated and monitored the reception of the virtual surveys. Surveys obtained from students from other professional programs were excluded.

The questionnaire comprised 48 questions and the estimate to complete was between 12 to $15 \mathrm{~min}$, previously checked in a pilot test. The first section comprised sociodemographic data (10 questions) including age, sex, careers, study funding, and housing situation; a next section for data related to their well-being within the framework of their educational environment in the COVID-19 context (10 questions); Another section requiring 
answers on whether they used or use didactic resources (2 questions). Finally, they were asked to answer 26 questions about satisfaction regarding the teaching-learning process with alternatives on the Likert scale of 5 alternatives: 1 . Very dissatisfied; 2 . Unsatisfied; 3 Neither Satisfied nor Dissatisfied; 4. Satisfied; and 5.Very Satisfied. The first column of Table 2 presents the list of questions asked.

Table 2. Factor analysis results.

\begin{tabular}{|c|c|c|c|}
\hline & Factor 1 & Factor 2 & Factor 3 \\
\hline \multicolumn{4}{|l|}{ SATISFACTION WITH SUPPORT AND ADAPTATION TO VIRTUAL MODALITY } \\
\hline $\operatorname{HSAY}\left({ }^{*}\right)$ was supported by your study program before the pandemic? Q19(**) & 0.770 & & \\
\hline HSAY with the way your university has handled the pandemic? Q18 & 0.695 & & \\
\hline HSAY with the general support of the university with online technology? Q15 & 0.679 & & \\
\hline HSAY regarding the commitment of the lecturer (s) in this virtual modality Q30 & 0.671 & & \\
\hline HSAY with the online library? Q17 & 0.627 & & \\
\hline $\begin{array}{c}\text { HSAY with adaptation of the tutors-professors/professors in their academic work in the face } \\
\text { of the pandemic? Q22 }\end{array}$ & 0.627 & & \\
\hline HSAY with the provision of university support services other than IT? Q16 & 0.620 & & \\
\hline HSAY Y with the use of technology used by the lecturer to facilitate learning? Q25 & 0.578 & & \\
\hline HSAY with the help of your career lecturers (program) during the pandemic? Q21 & 0.572 & & \\
\hline $\begin{array}{l}\text { HSAY regarding the understanding on the part of their lecturers in the face of connectivity or } \\
\text { equipment problems? Q38 }\end{array}$ & 0.569 & & \\
\hline $\begin{array}{l}\text { HSAY regarding the change of treatment received from the lecturers in this virtual modality? } \\
\text { Q24 }\end{array}$ & 0.543 & & \\
\hline \multicolumn{4}{|l|}{ SATISFACTION WITH INTERACTION IN THE VIRTUAL CLASSROOM } \\
\hline HSAY regarding communication with colleagues in this virtual mode? Q33 & & 0.781 & \\
\hline HSAY about openly expressing your doubts? in this virtual mode? Q31 & & 0.714 & \\
\hline HSAY regarding flexibility in the demands of lecturers? Q34 & & 0.708 & \\
\hline HSAY regarding motivation to study? Q35 & & 0.692 & \\
\hline HSAY regarding communication with the lecturer in this virtual modality? Q32 & & 0.689 & \\
\hline HSAY regarding time to reflect during class? Q39 & & 0.671 & \\
\hline HSAY with the interest, of your lecturers, regarding your health and well-being? Q40 & & 0.575 & \\
\hline HSAY regarding the duration of class sessions?Q29 & & 0.468 & \\
\hline \multicolumn{4}{|l|}{ SATISFACTION WITH THE DEVELOPMENT OF THE STUDY PROGRAM } \\
\hline HSAY regarding the type of evaluation in the virtual modality? Q36 & & & 0.796 \\
\hline HSAY regarding compliance with schedules in this virtual mode? Q27 & & & 0.757 \\
\hline HSAY regarding the ease of understanding of the courses in this virtual modality? Q26 & & & 0.687 \\
\hline HSAY regarding the variety of evaluation in the virtual modality? Q37 & & & 0.589 \\
\hline HSAY with your study program during the pandemic? Q20 & & & 0.548 \\
\hline HSAY regarding content compliance in this virtual modality? Q28 & & & 0.534 \\
\hline HSAY regarding the methodology of lecturers in this virtual modality? Q23 & & & 0.518 \\
\hline Total explained variance $=62.641$ & 52.887 & 5.386 & 4.368 \\
\hline Alpha & 0.93 & 0.908 & 0.897 \\
\hline
\end{tabular}

* HSAY: How satisfied are you. ${ }^{* *}$ Corresponding numbers in questionnaire. The first factor referring to institutional and teaching support and support, included 11 different items, shows a very high reliability with a Cronbach's alpha of 0.93 . These elements make up, as a whole, a dimension labeled as satisfaction with support and adaptation in the virtual mode. The scores for this dimension ranged from 11 to 55 , with a mean 37.35 , a median 38 , and a deviation of 8.74 . Such measures indicate that students assign it a medium/high satisfaction.

In order to manage the data and identify reasonable dimensions of student satisfaction, an exploratory factor analysis was performed for the 26 questions on satisfaction.

Compliance with the prerequisites to enable factor analysis was verified. A KaiserMeyer-Olkin (KMO) index of 0.958 (greater than 0.6) was obtained; for Bartlett's sphericity test less than 0.05 . Once the requirements were exceeded, the analysis of components with varimax orthogonal rotation produced a 3-factor structure that explains $62.64 \%$ of the accumulated variance. All but one of the factor loadings exceeds the value 0.5. The last three columns of Table 2 shows the results of the factor analysis. The 3 factors represent, in the COVID-19 context, satisfaction dimensions regarding: (i) support and adaptation 
to the virtual modality; (ii) interaction in the virtual classroom; and (iii) the development of study programs.

The second factor captured the interaction in the virtual classroom that occurs between students and the lecturer. It expresses communication between students, lecturer-student communication, motivation, interest, and reflection in the virtual classroom environment. It was composed of 8 items with high internal consistency (Cronbach's alpha $=0.91$ ), the dimension was labeled as satisfaction with Interaction in the virtual classroom. Among students, scores ranged from 8 to 40, mean 25.82, standard deviation 6.95, and median 26 . These measures indicate medium to high levels of satisfaction for this dimension.

The third factor includes aspects such as the type of evaluation, compliance with the schedule, understanding, methodology, and content. The incorporated responses generated a composition of 7 items that together also show a high index for internal consistency (Cronbach's alpha $=0.90)$. This composition has been identified as satisfaction with the development of the study program. The students' scores ranged from 7 to 35 , with an average score of 22.32, standard deviation of 5.88, and median 23. This dimension also reaches a medium to high level of satisfaction

\section{Results of Survey and Factor Analysis: Exploring Students' Satisfaction}

The outbreak of the COVID-19 pandemic caught LA HEIs between the 2020-I semester and the beginning of the 2020-II semester. The virtual modality was the response of the universities to the technological and connectivity service demands of the university community. In this section, we present the results of the survey starting with outlining some demographic characteristics of the groups in the three universities in Brazil, Colombia and Peru. We also present some experiences and well-being aspects brought to the surface as a consequence of the pandemic.

We then proceed to present the results of the level of satisfaction presented by the students according to the dimensions generated by the exploratory factor analysis. Such findings are presented below.

\subsection{Results of Sociodemographic Characteristics}

Regarding the sociodemographic characteristics of the university students: in Brazil, they were $57.68 \%$ women and $42.42 \%$ men, mostly under 23 years of age $(82.90 \%)$; in Colombia, $58.85 \%$ were women and $41.25 \%$ men, $100 \%$ being under 23 years of age; lastly, in Peru, $62.18 \%$ correspond to women and $36.13 \%$ men, mostly under 23 years of age $(89.90 \%)$. The undergraduate majors considered were Administrative Sciences and Accounting Sciences in Brazil (Uni-FACEF), Administrative Sciences and Government Finance and International Relations in Colombia (UEC), and Administrative Sciences and Commercial Engineering (UNJBG), evidenced in Table 3.

In relation to the year of study that students take and percentage of participation, in Brazil, first and fourth year (80\%); in Colombia, first and second year $(90 \%)$ and in Peru, second and third year (95\%). Regarding how they finance their studies, in Brazil, they work full time (38.4\%) and their parents pay for their studies (37.4\%). Students from Colombia and Peru state that their parents support their studies: $61.3 \%$ and $71.4 \%$ respectively.

Before the pandemic, students indicate that they lived with their families in Brazil and Peru with $94.9 \%$ and $93 \%$ respectively, and at the time of the survey, they continue to do so; the situation is somewhat different is in Colombia where $81.3 \%$ lived with their family before the pandemic and currently $93.8 \%$ do. 
Table 3. Demographic characteristics.

\begin{tabular}{ccccc}
\hline \multirow{2}{*}{ Gender } & & \multicolumn{3}{c}{ Country } \\
\cline { 2 - 4 } & Male & Brazil & Colombia & Peru \\
\hline \multirow{3}{*}{ Year } & Female & $42.42 \%$ & $41.25 \%$ & $36.13 \%$ \\
& Prefer not to say & $57.58 \%$ & $58.75 \%$ & $62.18 \%$ \\
& Less than 20 & $0.00 \%$ & $0.00 \%$ & $1.68 \%$ \\
\hline \multirow{3}{*}{ Disability } & $21-23$ & $35.35 \%$ & $80.00 \%$ & $50.42 \%$ \\
& $24-26$ & $47.47 \%$ & $20.00 \%$ & $39.50 \%$ \\
& 27 or more & $11.11 \%$ & $0.00 \%$ & $6.72 \%$ \\
& Yes & $6.06 \%$ & $0.00 \%$ & $3.36 \%$ \\
\hline \multirow{2}{*}{ Course } & No & $2.02 \%$ & $0.00 \%$ & $94.96 \%$ \\
& Did not say & $97.98 \%$ & $100.00 \%$ & $3.36 \%$ \\
& Accounting Sciences & $0.00 \%$ & $0.00 \%$ & $1.68 \%$ \\
\hline Administrative Sciences & $25.25 \%$ & $0.00 \%$ & $0.00 \%$ \\
Gevel of Study & $74.75 \%$ & $13.75 \%$ & $73.95 \%$ \\
& Com. Finance and Int. Relations & $0.00 \%$ & $86.25 \%$ & $0.00 \%$ \\
& Commercial Engineering & $0.00 \%$ & $0.00 \%$ & $26.05 \%$ \\
\hline & 1st. & $36.36 \%$ & $58.75 \%$ & $0.00 \%$ \\
& 2nd. & $8.08 \%$ & $40.00 \%$ & $50.42 \%$ \\
& 3rd. & $10.10 \%$ & $0.00 \%$ & $1.68 \%$ \\
& 4th. & $45.45 \%$ & $0.00 \%$ & $45.38 \%$ \\
& 5th. & $0.00 \%$ & $0.00 \%$ & $0.00 \%$ \\
\hline
\end{tabular}

Source: authors.

\subsection{Well-Being Outcomes within the Framework of Their Educational Environment}

Regarding aspects related to well-being within the framework of their educational environment in the current context, this study shows in the population of university students in Peru that 25.2\% have suffered from the COVID-19 disease or a direct member of their family compared to $17.2 \%$ in Brazil and 15\% in Colombia. Regarding other concerns in the midst of the COVID-19 pandemic, students from Brazil and Colombia indicate concern for mental health $37.4 \%$, and $41.3 \%$, for studies $35.4 \%$ and $33.80 \%$ and, for money, $34.3 \%$ and $26.3 \%$ respectively; in Peru $61.3 \%$ indicate concern about money, $40.3 \%$ about studies and $27.7 \%$ about mental health. Faced with the alternative of mentioning "other problems", there were, altogether, 50 responses (11 Brazilian, 25 Peruvian, and 14 Colombian) with coincidences for problems with the technological infrastructure, anxiety, stress, depression, staying at home, family, and illnesses (COVID-19 or other). Regarding whether they have disabilities, less than 5\% refer in Peru and Brazil (low vision, physical disability).

Despite the circumstances of the pandemic, most of the university students in the three countries indicate a positive attitude and on agreeing to incorporate more online aspects in the face-to-face learning activity when the pandemic ends, there is in Peru $71.4 \%$, Colombia $42.5 \%$, and Brazil 40.4\%. Regarding disagreement, it is presented in Brazil 38.4\%, Colombia $35 \%$, and Peru $11 \%$. In relation to feeling comfortable going back to university, the students of the three countries were mostly in agreement. When asked if they manage to balance studies with other commitments, including self-care responsibilities, more than $50 \%$ of Brazilians and Peruvians along with $35 \%$ of Colombians agreed.

In relation to didactic resources and learning experience, the most used teaching platforms are Zoom in Brazil and Colombia, and Google Meets in Peru. Before the closing in Brazil and Colombia, they used Moodle with $67.7 \%$ and $33.8 \%$, respectively. Regarding use for academic debates with forum, Brazil $36.4 \%$, Colombia 30\%, and Peru, 32.8\%. Use for Live conferences, Colombia 36.3\% and Peru 27.7\%.

\subsection{Satisfaction Results in the Virtual Modality Study}

In the measurement of the satisfaction variable in the virtual modality study in the COVID-19 context, 3 dimensions were included that showed high correlation with each 
other: support and adaptation in the virtual modality with interaction in the virtual classroom (0.79); support and adaptation in the virtual modality with development of the study program (0.804); finally, support and adaptation in the virtual modality with development of the study program (0.783).

\section{Discussion of Results}

One of the great challenges facing higher education institutions in the face of this pandemic situation is to prevent students from dropping out and to guarantee the quality of teaching. In Latin America, education opportunities in recent years with the efforts of governments have raised the figures for access to higher education in students of both sexes, although it is true not what was expected, close to $60 \%$ of students graduated in 6 years, with considerable variation by gender, ethnicity, and socio-economic level [31]. In Colombia, enrolment in university academic programs had already presented a downward curve that today in the face of the pandemic has accentuated [32,33], the same fate is emerging in Brazil, Peru, and Latin America in general and not only in enrolment but in terms of quality and equity [34].

The economic recession and the complex socio-health problem are aspects that, added to the effect of the pandemic, forced universities to implement strategies to meet the needs of the university community. Such efforts were aimed at maintaining spirits, motivation, well-being, allowing students to continue their studies and, above all, guaranteeing educational quality. This has led support to try to supply necessary physical resources, laptops, and Internet access, although these would not be the only concerns expressed by students in the study that reveal concern for their mental health and illness in the family [35-37].

Universities in their important social role in meeting the demands of supervisory bodies and concern for their own survival, have given importance to student satisfaction, recognizing that assessing it will contribute to making timely decisions in the face of management oriented to pursue the university quality [38]. In such a context, the power to keep the student body in the universities in the face of eminent desertion becomes more important, a problem that had been considered as the other pandemic that had already been afflicting the universities with its consequent social cost [39].

Various investigations have reported high and low levels of student satisfaction with the perceived quality of their studies $[40,41]$ where quality indicators guided their measurement. In this study, students were taught some elements related to the virtual modality educational environment linked to the context of the COVID-19 pandemic from their study experience. The study located 03 satisfaction factors, the first referring to support and adaptation to the virtual modality, the second to the interaction in the virtual classroom, and the third development of the study program.

The surveyed students from the three countries showed average satisfaction with the first factor related to the support they have received from their institutions. The health crisis has made visible multiple shortcomings of the face-to-face educational system such as the lack of materials, ICT equipment, and incomplete preparation of lecturers and students for the virtual modality of studies. This context exacerbated the academic, technological, and psychological demands, forcing universities to develop urgent implementation policies and support programs for students with IT equipment and connectivity problems. As time progresses, they try to respond to the difficulties and barriers that arise independently of a positive attitude towards technologies in teaching-learning [37,41]. It is evident that the conditions of opportunity are not the same for everyone [42]. It should be noted that the information collection period falls on almost the end of the first semester 2020.

The second factor shows the need for soft skills such as communication and interest of the lecturer on the well-being of the student; students from the three countries show medium to high satisfaction. There is similarity in their comments on the teaching-learning perceived preoccupations of their lecturers, where they state: "That lecturers are more understanding with the schedule", "I hope better communication from lecturers to students", "That they are more flexible", "That they be empathetic in the face of technology difficul- 
ties", "More tolerance, solidarity, and understanding of lecturers", and "Greater dynamism in the classroom". What is expressed is unique since the bonding in the classroom is part of and articulated in a learning context. In the area of human development, researchers agree that "no one can replace the humanity of the lecturer in the classroom" [43,44]. This space of inter-subjectivity corresponds to a lecturer-student involvement [45] that will delimit the degree of cognitive and emotional satisfaction and consequently educational achievement [46].

The third factor related to the study program considered the elements of satisfaction based on content, methodology, understanding of virtual courses, evaluation, and compliance with schedules. This approach to the pedagogical-disciplinary field obtained average satisfaction. Since the pandemic began, the role of the lecturer had a great turn, being forced from one moment to another to assume the commitment to transform and adapt to the challenge of using new technologies in this teaching modality, which does not mean that the benefits that virtual education means (e-learning) can offer are not recognized [47]. In this context, some commentators have questioned the term 'teaching-learning process under virtual modality'. The Vice-Chancellor (or Rector as it is called in LA HEIs) of the University of Quimes, Alejandro Villar [42] suggests the term 'remote teaching'. This is because, in reality, there has been a rapid and heterogeneous response to the pandemic and "an explicit agreement where students and lecturers accept the advantages and limitations of this modality".

The findings in this third factor cannot be ignored; this study allows us to have as a primary source, an approach to student satisfaction about their study program, about the response of their institution and their lecturers to this new scenario. All lecturers had to adapt to the lack of familiarity in this modality, as stated by Fernández-Regueira et al. [48] on whether the lecturer has taught online; shows that $68.07 \%$ have never done it, and they bet on a methodology and evaluation based on content transmission and present conceptual incoherence in the didactic dimensions of their proposals.

The interest in satisfaction measures is not recent, the institutions have been conducting evaluations in this regard during the pandemic. Some HEI decided to carry them out with the pertinent modifications, considering that it is unlikely to lift the state of emergency soon to go to complete normality. Satisfaction measurements are shown as a very useful tool to adapt to the conditions of each educational program due to the lack of knowledge about how the next academic year 2021 will develop [49].

\section{Conclusions, Final Remarks, Limitations, and Further Research}

In this paper, we reflect on the critical situation faced by Latin American universities as a consequence of the pandemic. Using simple systemic tools as rich pictures, we make sense of the complex situation and extract relevant systems of concern for the different stakeholders. We locate student satisfaction as an issue important to explore and measure to assess the usefulness of the online mode of teaching adopted due to the disruption caused by COVID-19.

Using a sample of 298 students from three of the countries more severely hit by the pandemic: Brazil, Colombia, and Peru, the article analyzes satisfaction towards online teaching using the following variables: (a) Well-being, educational resources, and learning experience; (b) General satisfaction with virtual classes. We applied exploratory factor analysis to these variables and identified three dimensions or clusters: (i) satisfaction with support and adaptation in the virtual mode; (ii) satisfaction with the interaction in the virtual classroom; and (iii) satisfaction with the development of the study program. Average scores for the dimensions indicate moderate/high levels of satisfaction. Our findings suggest that there are still unmet needs in relation to access to digital resources and socio-emotional needs. We are aware that due to the limitations of the sample size, it is not possible to generalize these results but nevertheless our findings, we believe will have the following implications which are relevant to lecturers and educational planners interested in teaching and learning in post pandemic times. 


\subsection{Policy Implications}

Undoubtedly, one of the greatest consequences of the pandemic in the world is the economic recession that directly affected families with the smallest economy in Latin America. This aspect is manifested in the current situation of the students of the three universities sampled here, showing that more than a third in Brazil work to meet their expenses and more than $60 \%$ in Colombia and Peru are dependent on their parents who pay for their maintenance and studies. Thus, guaranteeing the continuity of studies is a latent problem, added to the health aspect. An important concern expressed is, even before money, mental health and the concern of being able to face this crisis that demands greater speed of adaptation in order to maintain the close "known normality".

This situation shows clearly the weaknesses and, shortcomings of the universities regarding the use of teaching platforms, digital tools, and lecturer training. This has forced governments to implement policies that respond to demanding needs. However, despite the efforts of the universities to support the demands raised due to the pandemic, there is still a long way to go.

In this study, the aim was to answer research questions related to students' satisfaction. (How satisfied are students with the new teaching arrangements and how these can be improved?) We did this to provide some evidence so the elements of the teaching-learning process can be enhanced, corrected, and improved in the next academic periods. Our findings indicate that there are still students who did not receive support from their institution on methodological management, bonding, and communication in the classroom. It is important to consider guaranteeing the safety, quality of teaching, and equal opportunities for educational institutions that face all these challenges in this context and strive to adapt for the benefit of their university community.

They also perceive the lack of understanding in the face of all the problems that continue their studies in the conditions of equipment failures and situations of health problems implies for them, which demands the understanding and flexibility of its lecturers. These aspects are important in the sense that the quality of the lecturer-student bond, the human climate, and lecturer support contribute to student learning.

\subsection{Final Remarks, Systems Thinking and Multi-Methodological Practice, Limitations, and Further Work}

Our study has shown that the systemic view taken has allowed us to explore one of the key stakeholders (students) immersed in this complex situation in which a myriad of variables interact. There are multi perspectives, many conflicting interests, and several implementation difficulties. In education, we highlight the problems involving need for technological platforms, problems with the incorporation of new digital technologies in classrooms, the connectivity difficulties of the online modality, the lack of equipment, and acceptance or rejection of the online modality by students. In addition, on top of all of this, there are mounting problems involving stress, anxiety for both students, staff, and university planners.

In this paper, we propose a systemic approach to explore the complexities of the new ways of teaching under the impact brought on by the pandemic. We linked some features of SSM with statistical analysis to give some indication as to how satisfied students are with the new ways of delivering the teaching material. We argued, following Mingers [19,20], that the multi-methodological practice in which methods from both hard and soft spectrum of management science are brought together under a systemic framework, can shed light into a complex situation. We believe that many multi-method applications draw only on different systems approaches, but it is perfectly legitimate to draw on a mix of systems, social science approaches and methods from the hard end of the spectrum. Using systems thinking principles does not equate with using systemic methods as such and that what makes a project systemic is how it is approached and not where the methods originated from. 
Furthermore, systems thinking underpinning multi-methodological practice provides a backdrop and allows the participants to 'immerse' their minds and their actions when trying to have a systemic view of the problem(s) in front of them, and that is the contribution to the systems community that this paper proposed and we believe that we have followed these commitments in the paper. Systems thinking by its nature should encourage multi-perspectives to flourish. In our experience of practicing multi-methodology using systems thinking principles, see [50-52], one way of facilitating those is to assemble a multidisciplinarily team. This project has been the product of a multi-disciplinary effort: One author is fully conversant on soft approaches and systems thinking practice [51-53]; one is expert in education [54]; other one is fairly familiar with applications of systems thinking in sustainability and public policy [55]; other in statistical analysis [56]; and international education formed the rest of the team. On reflection, at end of our exercise, the authors who were not familiar with systems thinking saw the benefits that this can bring and felt that they have acquired a useful tool to tackle complexity in future projects.

Finally, our contribution to the systems community can be summarized as follows: Based on commentators who advocate the use of systems thinking underpinning multimethodological practice $[19,20,26]$ and the evaluation of complex projects where multiple contexts were defined [57], we have designed a systemic framework to explore a complex problem (new ways of teaching under pandemic constrains). We conclude that the pandemic has brought a myriad of issues affecting the teaching and we have focus on one 'relevant' issue which is 'students satisfaction' and use some statistical analysis which provided some results that shed some light as an initial way to understand this problem. The results were brought back and discussed on the wider context of the pandemic impact in an attempt to ascertain which other issues might be worth pursuing using systemic approaches in future research. We do hope that readers will assess and value the use using systemic principles when using a tool of methods when tackling complexity.

This study has one important limitation. The study used a small sample of universities, which prevents making inference to the universe of universities in the countries involved. Likewise, it does not deepen in relation to the teaching-learning methodologies but it is oriented to make known the satisfaction of the students in front of the virtual modality in their studies.

The limitation mentioned is not impossible to address, so a suggestion as a future study is to consider first to explore further what systemic implications students' satisfaction has brought to the fore. A future study should consider and discuss these issues against the initial findings presented here. This exploration as well the use of a larger sample can render a fuller view of this complex and problematic situation.

Finally, and although the questionnaire used (See Appendix A) contains a number of closed questions which have been used for the exploratory factorial analysis, it also contains a number of open questions. Interviewers have engaged fully with these open questions (see questions 45 to 47 in Appendix A) providing rich data about the feelings and perceptions of studying under pandemic conditions. This analytical approach concentrates on quantitative data, which can certainly be regarded as a limitation of the study. However, we plan to use these data in a future study using a qualitative approach. Analyzing these responses will indeed complement the systemic perspective taken in this study in that it will give scope to discuss the interrelations between quantitative variables useful to improve the performance of the processes used by the three universities and also will help to understand the perceptions of the students in a pot-pandemic environment.

Author Contributions: Conceptualization, S.Q.-P., M.F.C.-B., A.P.-C. and H.H.R.-J.; Formal analysis, S.Q.-P., M.F.C.-B., M.C.-R. and A.P.-C.; Methodology, S.Q.-P., M.F.C.-B., M.C.-R. and A.P.-C.; Software, S.Q.-P. and M.C.-R.; Visualization, M.F.C.-B.; Writing-original draft, M.F.C.-B., M.C.-R. and A.P.-C.; Writing-review \& editing, M.F.C.-B. and M.C.-R. All authors have read and agreed to the published version of the manuscript.

Funding: This research received no external funding. 
Institutional Review Board Statement: Not applicable.

Informed Consent Statement: Informed consent was obtained from all subjects involved in the study.

Data Availability Statement: The data presented in this study are available on request from the corresponding author.

Acknowledgments: All authors are grateful to Katarzyna Werner-Masters for her helpful comments on an earlier draft of the questionnaire used in this paper.

Conflicts of Interest: The author declares no conflict of interest.

\section{Appendix A. The COVID-19 Experience of HEI Students in South America}

Appendix A.1. Socio Demographic

1. Indicate the university you are studying at.

2. Indicate which career you are studying.

3. What is your current level of undergraduate study?
- a. Year 1
- b. Year 2
- c. Year 3
- d. Year 4
- $\quad$ e. Year 5

4. How do you finance your studies (including tuitions, the cost of student accommodation, books, etc.)?

- a. Scholarship

- b. Part-time job

- c. Full-time job

- d. My parents pay for it

5. Where did you live before the pandemic?

- a. Student residence

- b. With own family

- c. Rented house or flat

- d. Other:

5A. Where do you live now?

- a. Student residence

- b. With own family

- c. Rented house or flat

- d. Other:

6. Please select your gender.

- a. Female

- b. Male

- c. Prefer not to say

7. What is your age? [Indicate on a scale]

- a. Less than 20

- b. 21-23

- c. 24-26

- d. 27 or more

8. Do you have any disability?

- $\quad$ a. Yes

- b. No

- c. Prefer not to say

9. If you answered "Yes" in the previous question, what kind of disability do you have? 
Appendix A.2. Well-Being within the Framework of Your Educational Environment in the COVID19 Context

10. Did you or any of your immediate family members (parents and siblings) suffer or are you suffering from COVID-19 during the study period?

- $\quad$ a. Yes

- b. No

11. Did you experience or are you experiencing any other concerns amid COVID-19? [you can check more than one box)*

- $\quad$ a. Yes, I have had accommodation issues

- b. Yes, I have had study issues

- c. Yes, I have had money issues.

- d. Yes, I have had mental health issues.

- $\quad$ e. I have had no issues.

- f. I prefer not to say.

- g. Other problems.

12. If you indicated the presence of other problems in the previous question, explain what these concerns were and how did they affect you?

Appendix A.3. Didactic Resources and Learning Experience of Your Institution

13. Since the university moved to online teaching, have you been exposed to any of the following teaching platforms [Tick all that apply]

- $\quad$ a. Live lectures via Zoom

- b. Live lectures via MS Teams

- c. Live lectures via Google Meets

- d. Other

14. Which of the resources below were used by your university before closing? [Tick all that apply]

- $\quad$ a. Live lectures via Zoom, MS Teams or other

- b. Academic discussions via Forums

- c. Use of the Moodle platform

- d. Seminars and/or pre-recorded tutorials.

- $\quad$ e. Topic-focused podcasts

- $\quad$ f. none

Appendix A.4. Satisfaction

Five-choice response from Very Unsatisfied to Very Satisfied

1. Very unsatisfied

2. Unsatisfied

3. Neither satisfied nor unsatisfied

4. Satisfied

5. Very satisfied 
Table A1. Satisfaction.

\begin{tabular}{|c|c|c|c|c|c|c|}
\hline $\mathbf{N}^{\circ}$ & STATEMENTS & 1 & 2 & 3 & 4 & 5 \\
\hline 15. & How satisfied are you with the university's general support for online technology? & & & & & \\
\hline 16. & $\begin{array}{l}\text { How satisfied are you with the delivery of university support services other than IT } \\
\text { (e.g., well-being, counselling, finance office, etc.) during the lockdown? }\end{array}$ & & & & & \\
\hline 17. & How satisfied are you with online library? & & & & & \\
\hline 18. & How satisfied are you with the way your university adapted during the pandemic? & & & & & \\
\hline 19. & How satisfied were you with your study program before the pandemic? & & & & & \\
\hline 20. & How satisfied are you with your study program during the pandemic? & & & & & \\
\hline 21. & $\begin{array}{l}\text { How satisfied are you with the help of your career tutors/lecturers } \\
\text { during the pandemic? }\end{array}$ & & & & & \\
\hline 22. & $\begin{array}{l}\text { How satisfied are you with the adaptation of the tutors/lecturers in their academic } \\
\text { work in the face of the pandemic? }\end{array}$ & & & & & \\
\hline 23. & How satisfied are you with the methodology of the lecture in this virtual modality? & & & & & \\
\hline 24. & $\begin{array}{l}\text { How satisfied are you with the commitment of the lecturer (s) } \\
\text { in this virtual modality? }\end{array}$ & & & & & \\
\hline 25. & How satisfied are you with the technology used by the lecturer to facilitate learning? & & & & & \\
\hline 26. & $\begin{array}{l}\text { How satisfied are you with the ease of understanding the courses } \\
\text { in this virtual modality? }\end{array}$ & & & & & \\
\hline 27. & How satisfied are you with compliance with schedules in this virtual modality? & & & & & \\
\hline 28. & How satisfied are you with the content compliance in this virtual modality? & & & & & \\
\hline 29. & How satisfied are you with the duration of class sessions? & & & & & \\
\hline 30. & How satisfied are you with the treatment of lectures in this virtual modality? & & & & & \\
\hline 31. & $\begin{array}{l}\text { How satisfied are you with being exposed to openly expressing your doubts in the } \\
\text { virtual modality? }\end{array}$ & & & & & \\
\hline 32. & How satisfied are you with communication with the lecturer in this virtual modality? & & & & & \\
\hline 33. & How satisfied are you with communication with classmates in this virtual modality? & & & & & \\
\hline 34. & How satisfied are you with regard to the flexibility of the lecturers' demands? & & & & & \\
\hline 35. & How satisfied are you with the motivation to study? & & & & & \\
\hline 36. & How satisfied are you with the evaluation modality? & & & & & \\
\hline 37. & How satisfied are you with regards to the variety in the evaluation modality & & & & & \\
\hline 38. & $\begin{array}{l}\text { How satisfied are you with your lecturers understanding of connectivity or } \\
\text { equipment problems? }\end{array}$ & & & & & \\
\hline 39. & How satisfied are you with time to reflect during the class? & & & & & \\
\hline 40. & $\begin{array}{l}\text { How satisfied are you regarding the lecturer's attitude/interest regarding health } \\
\text { and wellness? }\end{array}$ & & & & & \\
\hline
\end{tabular}

\section{Appendix A.5. Future Expectations}

Five-choice response from:

1. Strongly disagree

2. Disagree

3. Neither agree nor disagree

4. Agree

5. Strongly agree 
Table A2. Future Expectations.

\begin{tabular}{|c|c|c|c|c|c|c|}
\hline $\mathbf{N}^{\circ}$ & STATEMENTS & 1 & 2 & 3 & 4 & 5 \\
\hline 41. & I am managing to keep positive despite the current situation. & & & & & \\
\hline 42. & $\begin{array}{l}\text { When the pandemic ends and face-to-face teaching is possible again, I } \\
\text { would like to incorporate more aspects online into the learning activity. }\end{array}$ & & & & & \\
\hline 43. & I would feel comfortable returning to campus over the coming months. & & & & & \\
\hline 44. & $\begin{array}{c}\text { I am managing to balance my studies with other commitments, including } \\
\text { caring responsibilities }\end{array}$ & & & & & \\
\hline
\end{tabular}

45. What are your learning expectations during the pandemic?

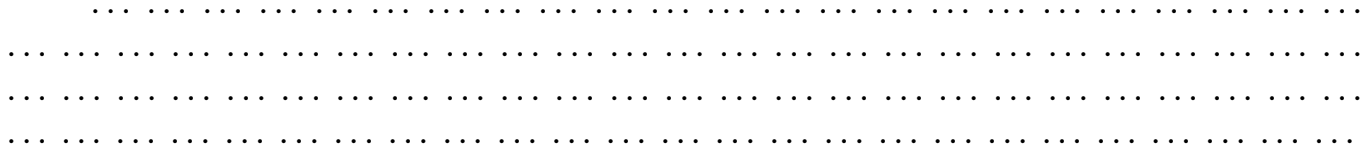

46. What are your learning expectations for after the pandemic?

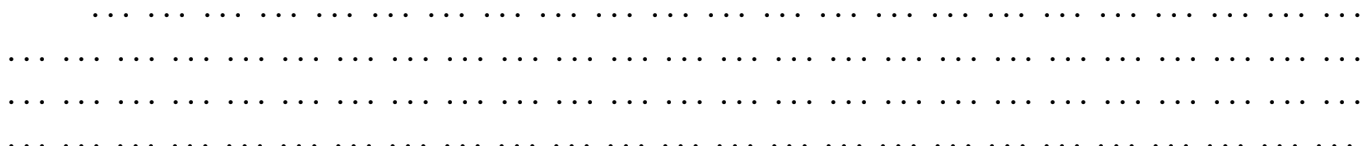

47. Please provide any additional comments that you consider important in order to improve teaching and learning in these times of a pandemic.

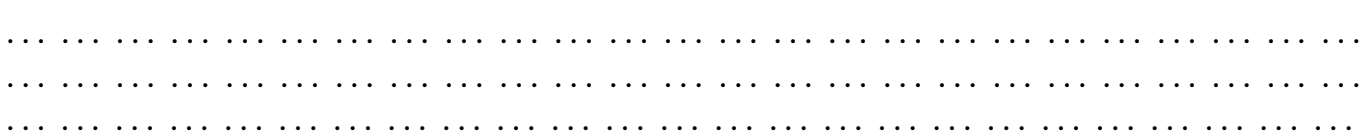

\section{References}

1. Johns Hopkins University. COVID-19 Dashboard by the Center for Systems Science and Engineering (CSSE) at John Hopkins University. 2020. Available online: https://gisanddata.maps.arcgis.com/apps/opsdashboard/index.html\#/bda7594740fd402 99423467b48e9ecf6 (accessed on 14 November 2020).

2. UNESCO-IESALC. Informe CEPAL, OREALC y UNESCO: «La Educación en Tiempos de la Pandemia de COVID-19»-UNESCOIESALC. 2020. Available online: https: / / www.iesalc.unesco.org/2020/08/25/informe-cepal-y-unesco-la-educacion-en-tiemposde-la-pandemia-de-covid-19/ (accessed on 14 November 2020).

3. World Bank. The COVID-19 Crisis Response: Supporting Tertiary Education for Continuity, Adaptation, and Innovation; World Bank: Washington, DC, USA, 2020. Available online: https://openknowledge.worldbank.org/handle/10986/34571 (accessed on 23 December 2020).

4. Banco Mundial. La Educación Superior se Expande en América Latina y el Caribe, Pero Aún no Desarrolla Todo su Potencial [Internet]. Comunicado de Prensa. 2017. Available online: https://www.bancomundial.org/es/news/press-release/2017/05/17 /higher-education-expanding-in-latin-america-and-the-caribbean-but-falling-short-of-potential (accessed on 2 October 2020).

5. Guerrero, S.; Soto, D. La política educativa en torno a la masifcación de la educación superior y su relación con el abandono universitario en Colombia. Rev. Hist. Educ. Latinoam. 2019, 21, 109-135. [CrossRef]

6. Chacón, M. Informe Revela Disminución de Estudiantes Matriculados en Universidades de Colombia-Educación-VidaELTIEMPO.COM. El Tiempo. 2020. Available online: https:/ /www.eltiempo.com/vida/educacion/informe-revela-disminucionde-estudiantes-matriculados-en-universidades-de-colombia-526992 (accessed on 10 October 2020).

7. Sobrinho, J.; Brito, M. La educación Superior en Brasil: Principales tendencias y desafíos. Rev. Aval. Educ. Super. (Camp.) 2008, 13, 487-507. [CrossRef]

8. Noguera, P. Estudio en Brasil Revela que 42\% de los Alumnos Abandonaría Universidades Privadas por la COVID-19. ANADOLU AGENCY. 2020. Available online: https://www.aa.com.tr/es/mundo/estudio-en-brasil-revela-que-42-de-losalumnos-abandonaria-universidades-privadas-por-la-covid-19/1873890 (accessed on 10 October 2020). 
9. British Council. La Reforma del Sistema Universitario Peruano: Internacionalización, Avance, Retos y Oportunidades [Internet]. 2016. Available online: https://www.britishcouncil.pe/sites/default/files/la_reforma_del_sistema_universitario_peruano_-_ internacionalizacion_avance_retos_y_oportunidades.pdf (accessed on 10 October 2020).

10. INEI. PERÚ Instituto Nacional de Estadística e Informática. Número de Matriculados. 2017. Available online: https://www.inei. gob.pe/buscador/?tbusqueda=universidades (accessed on 10 October 2020).

11. El Peruano. Clases Semipresenciales a Partir del Próximo Año. 30 September 2020. Available online: https://elperuano.pe/ noticia/104569-clases-semipresenciales-a-partir-del-proximo-ano (accessed on 10 October 2020).

12. UNESCO. COVID Impact on Education. Global Monitoring of School Closures Caused by COVID-19. 2020. Available online: https: / / en.unesco.org/covid19/educationresponse (accessed on 10 November 2020).

13. Garcés, J.; Mora, C. Estrategias de aprendizaje para mitigar la deserción estudiantil en el marco de la COVID-19. Rev. Discip. Cienc. Econ. Soc. 2020, 2, 49-55.

14. Jiménez, E. Retos de la Universidad ante las segunda ola de la pandemia. Educaweb.com. Available online: https://www. educaweb.com/noticia/2020/10/21/retos-universidad-coronavirus-19337/ (accessed on 22 October 2020).

15. Aristovnik, A.; Keržič, D.; Ravšelj, D.; Tomaževič, N.; Umek, L. Impacts of the COVID-19 Pandemic on Life of Higher Education Students: A Global Perspective. Sustainability 2020, 12, 8438. [CrossRef]

16. Sánchez, J. Satisfacción Estudiantil en Educación Superior: Validez de su Medición, Santa Marta; Universidad Sergio Arboleda: Bogotá, Columbia, 2018. Available online: https: / / repository.usergioarboleda.edu.co/bitstream/handle/11232/1027/SATISFACCI\% C3\%93N\%20ESTUDIANTIL.pdf?sequence $=4 \&$ isAllowed $=y$ (accessed on 10 October 2020).

17. Merino-Soto, C.; Dominguez-Lara, S.; Fernández-Arata, M. Validación inicial de una Escala Breve de Satisfacción con los Estudios en Estudiantes Universitarios de Lima. Educ. Méd. 2017, 18, 74-77. [CrossRef]

18. Rosario-Rodríguez, A.; González-Rivera, J.A.; Cruz-Santos, A.; Rodríguez-Ríos, L. Demandas Tecnológicas, Académicas y Psicológicas en Estudiantes Universitarios Durante la Pandemia por COVID-19. Rev. Caribeña Psicol. 2020, 4, 176-185. [CrossRef]

19. Mingers, J.; Gill, A. (Eds.) Multi-Paradigm Multimethodology. In Multimethodology: Towards Theory and Practice and Mixing and Matching Methodologies; Wiley: Chichester, UK, 1997; pp. 1-20.

20. Mingers, J.; Gill, A. (Eds.) Towards critical pluralism. In Multimethodology: Towards Theory and Practice and Mixing and Matching Methodologies; Wiley: Chichester, UK, 1997; pp. 407-440.

21. Ackoff, R. Transforming the Systems Movement. Syst. Think. 2004, 15, 2-5.

22. Kim, D.H. Introduction to Systems Thinking; Pegasus Communications (now Leverage Networks Inc.): Waltham, MA, USA, 1999; ISBN 1-883823-34-X. Available online: https:/ / thesystemsthinker.com/wp-content/uploads/2016/03/Introduction-to-SystemsThinking-IMS013Epk.pdf (accessed on 10 October 2020).

23. Reynolds, S. COVID-19 Means Systems Thinking Is No Longer Optional; New Philanthropy Capital 477 (NPC): London, UK, 2020. Available online: https:/ / www.thinknpc.org/blog/covid-19-means-systems-thinking-is-no-longer-optional/ (accessed on 28 September 2020).

24. Bradley, D.T.; Mansouri, M.A.; Kee, F.; Garcia, L.M.T. A systems approach to preventing and responding to COVID-19. EClinicalMedicine 2020, 21, 100325. [CrossRef] [PubMed]

25. OECD. Policy Responses to Coronavirus (COVID-19). A Systemic Resilience Approach to Dealing with COVID-19 and Future Shocks. 2020. Available online: http:/ / www.oecd.org/coronavirus/policy-responses/a-systemic-resilience-approach-to-dealingwith-covid-19-and-future-shocks-36a5bdfb / (accessed on 28 September 2020).

26. Mingers, J.; Brocklesby, J. Multimethodology: Towards a Framework from Mixing Methodologies. Omega Int. J. Manag. Sci. 1997, 25, 489-509. [CrossRef]

27. Churchman, C.W. Wicked Problems. Manag. Sci. 1967, 14, B-141-B-146.

28. Rittel, H.W.; Webber, M.M. Dilemmas in a General Theory of Planning. Policy Sci. 1973, 4, 155-169. [CrossRef]

29. Checkland, P.B. Systems Thinking, Systems Practice; Wiley: Chichester, UK, 1981.

30. UK Open University. The Art of Rich Pictures. 18 September 2012. Available online: https://www.open.edu/openlearn/sciencemaths-technology/engineering-technology/the-art-rich-pictures (accessed on 2 October 2020).

31. Kirp, D. The College Dropout Scandal. The Chronicle Review; University Oxford: Oxford, UK, 2019. Available online: https: / / www.chronicle.com/article/the-college-dropout-scandal/ (accessed on 20 October 2020).

32. Taborda, C. Educación Superior en Cuidados Intensivos por Coronavirus. EL ESPECTADOR. El Espectador. 2020. Available online: https: / www.elespectador.com/coronavirus/educacion-superior-en-cuidados-intensivos-por-coronavirus-articulo-91 $6419 /$ (accessed on 10 October 2020).

33. Meléndez, P.; Ramirez, L.; Escobar, S. Una Universidad de Hormigas: Formulación de Políticas de Admisión en un Programa Universitario. 2020. Available online: https:/ /www.researchgate.net/publication/344961982_Una_universidad_de_hormigas_ formulacion_de_politicas_de_admision_en_un_programa_universitario (accessed on 10 November 2020).

34. Pedró, F. COVID-19 Y Educación Superior En América Latina Y El Caribe: Efectos, Impactos Y Recomendaciones Políticas. Fund. Carol. 2020. [CrossRef]

35. DeMatthews, D.; Knight, D.; Reyes, P.; Benedict, A.; Callahan, R. From the Field: Education Research during a Pandemic. Educ. Res. 2020, 49, 398-402. [CrossRef] 
36. Cycle Lights. Evitar deserción, reto de Universidades frente a la pandemia. Cancún Mexico. 2020. Available online: https: / /lucesdelsiglo.com/2020/11/05/evitar-desercion-reto-de-universidades-frente-a-la-pandemia-local/ (accessed on 5 November 2020).

37. Kuhfeld, M.; Soland, J.; Tarasawa, B.; Johnson, A.; Ruzek, E.; Liu, J. Projecting the Potential Impact of COVID-19 School Closures on Academic Achievement. Educ. Res. 2020, 49, 549-565. [CrossRef]

38. Surdez, E.G.; Sandoval-Caraveo, M.C.; del Carmen Sandoval-Caraveo, M.; Lamoyi-Bocanegra, C.L. Satisfacción estudiantil en la valoración de la calidad educativa universitaria. Educ. Educ. 2018, 21, 9-26. [CrossRef]

39. Cortés, S.; Alvarez, P.; Llanos, M.; Castillo, L. CI Deserción universitaria: La epidemia que aqueja a los sistemas de educación superior. Rev. Perspect. 2019, 20, 13-25. [CrossRef]

40. Cadena-Badilla, M.; Acosta, A.M.; Vega-Robles, A.; Quiroga, J.V. La satisfacción estudiantil universitaria: Análisis estratégico a partir del análisis de factores. Ind. Data 2016, 18, 9. [CrossRef]

41. Sanz, I.; Sáinz, J.; Capilla, A. Efectos de la Crisis del Coronavirus en la Educación. Organ. Estados Iberoam. Para Educ. Cienc. Cult. 2020, 10-12. Available online: https://www.oei.es/Ciencia/Noticia/oei-analiza-como-afectara-el-cierre-colegios-coronavirus (accessed on 10 October 2020).

42. Villar, A. Universidad y Pandemia: De la Educación Remota de Emergencia a la Modalidad Virtual. Página 12, 12 November 2020. Available online: https://www.pagina12.com.ar/305125-universidad-y-pandemia-de-la-educacion-remota-deemergencia-(accessed on 12 November 2020).

43. Rodríguez-Garcés, C.; Padilla Fuentes, G.; Gallegos Fuentes, M. Calidad educativa, apoyo docente y familiar percibido: La tridimensionalidad de la satisfacción escolar en niños y adolescentes. Cuad. Investig. Educ. 2020, 11, 157-173. [CrossRef]

44. Mege, A. La Educación que No Se Tiene. La Tribuna, 10 November 2020. Available online: https://www.latribuna.cl/opinion/20 20/11/10/la-educacion-que-no-se-tiene.html(accessed on 10 November 2020).

45. Villalobos, J.L.; Flórez, G.A.; Londoño, D.A. La escuela y la familia en relación con el alcance del logro académico. La experiencia de la Institución Educativa Antonio José de Sucre de Itagüí (Antioquia) 2015. Aletheia. Rev. Desarro. Hum. Educ. Soc. Contemp. 2017, 9, 58-75. [CrossRef]

46. Garnica, J.V.O.; Torres, K.M.P. El Nivel de Satisfacción Escolar y su Relación con la Orientación Vocacional en Alumnos de Psicología Educativa. 2010, p. 173. Available online: http:/ /200.23.113.51/pdf/27385.pdf (accessed on 10 November 2020).

47. Casademont, J. Reflexiones de un docente ante la situación de pandemia de COVID-19. Rev. Fund. Educ. Méd. 2020, 23, 107. [CrossRef]

48. Fernández-Regueira, U.; Gewerc, A.; Llamas-Nistal, M. El profesorado universitario de galicia y la enseñanza remota de emergencia: Condiciones y contradicciones The university lecturers of galicia and remote emergency teaching: Conditions and contradictions. Campus Virtuales 2020, 9, 9-24.

49. Román, E. La evaluación del profesorado universitario en tiempos de pandemia: Los sistemas online de gestión de encuestas de satisfacción estudiantil. Campus Virtuales 2020, 9, 61-70.

50. Françozo, R.; Paucar-Caceres, A.; Belderrain, C. Using Value-Focused Thinking to assist Soft Systems Methodology' transformation selection: Structure Systemic Planning in a Special Educational Needs School. J. Oper. Res. Soc. 2021, in press.

51. Paucar-Caceres, A.; Wright, G.; Ribeiro dos Santos, P.; Neyra Belderrain, M.C. A 'Soft' Situational Strategic Planning Model for Brazilian Municipal Governments. J. Oper. Res. Soc. 2020, 71, 363-380. [CrossRef]

52. Castellini, M.A.; Paucar-Caceres, A. A Conceptual Framework for Integrating Methodologies in Management: Partial Results of a Systemic Intervention in a Textile SME in Argentina. Syst. Res. Behav. Sci. 2018. [CrossRef]

53. Abuabara, L.; Paucar-Caceres, A.; Neyra Belderrain, M.C.; Burrowes-Cromwell, T. Combining Soft OR Approaches to Support the Re-designing of a Teamwork Strategy: An Aviation Manufacturer Brazilian Company Case. J. Oper. Res. Soc. 2018, 69, 220-234. [CrossRef]

54. Cavalcanti-Bandos, M.F.; Quispe-Prieto, S.; Paucar-Caceres, A.; Rojas-Jiménez, H.H.; Burrowes-Cromwell, T. Education for Sustainable Development in Business Programmes in Latin America: Case studies of three HEIs in Brazil, Colombia and Peru. Int. J. Sustain. High. Educ. 2021. forthcoming. Revised and Re-submit (February 2021).

55. Cavalcanti-Bandos, M.; Paucar-Cáceres, A. An Ecological Vision with Social Responsibility in the Sustainable Environment: Promoting Ecological and Environmental Awareness in Centro Universitário Municipal de Franca-Uni-FACEF (Sao Paulo). In Social Responsibility and Sustainability: Addressing Challenges and Creating Opportunities; Filho, W.L., Ed.; World Sustainability Series; Springer: Berlin/Heidelberg, Germany, 2021.

56. Quispe-Prieto, S.; Caipa-Ramos, M.; Salas-Hallasi, S.; Salvador-Oré, K.; Romani, F. Practices and knowledge about primary prevention of tuberculosis in university students of health sciences in the Tacna region, Peru. An. Fac. Med. 2019, 80, 475-481. [CrossRef]

57. Midgley, G.; Rajagopalan, R. Critical Systems Thinking, Systemic Intervention and Beyond. In The Handbook of Systems Science; Kijima, K., Deguchi, H., Metcalf, G., Eds.; Springer: New York, NY, USA, 2021; in press. 